\title{
The impact of penicillin on sexual healthcare delivery systems in mid-20th century Britain
}

Penicillin's introduction in 1943 as a simple, inexpensive cure for syphilis had notable influences on venereology and broader sexual healthcare systems. Foremost among these was the perception that venereal disease (VD) no longer posed a threat and therefore merited fewer resources for control. As the chairman of a regional hospital board replied, when asked about reconstructing a VD clinic in 1958: "We don't want to spend money on these dying diseases". ${ }^{1}$ While venereology had developed as a specialty in part because of Salvarsan, general practitioners could easily provide penicillin to patients. Thus, penicillin's success left some venereologists reflecting that they had worked themselves out of a profession. One noted:

The British venereologist... may perhaps be compared with the fighter pilot whose aircraft has been shot down from under him, and who is parachuting slowly down to earth wondering the while how this happened and what he will do when he lands....he has been in the dual position of defender and attacker of his own aircraft. ${ }^{2}$

Drastic decreases in syphilis cases in the late 1940 s and early 1950 s led to a waning in associated intellectual curiosity. As a result, venereology journals were shut down and the ranks of venereologists noticeably thinned. By 1955, only nine senior venereology registrars remained across England. ${ }^{1}$ One London hospital reported that venereology had become a fragmented service without any full-time staff. ${ }^{3}$ All syphilisfocused disciplines (internal medicine, obstetrics, psychiatry and public health) were reoriented towards their non-syphilis activities and academic momentum swayed towards chronic diseases. ${ }^{2}$ In challenge to venereology's fading prominence, the UK Ministry of Health argued that: "diagnosis and treatment of venereal diseases constitute a separate clinical speciality, and should not be left to become a minor interest of specialists in other fields". "Yet, despite such defences, that is what happened.

Venereology's decline, however, did not reflect an absence of risk and, by the late 1950 s, syphilis cases resurged. While historical accounts attributed some of this rise to growing numbers of black immigrants and increasing unsafe homosexual sex, ${ }^{5}$ the disassembly of VD healthcare 
infrastructure was also key. ${ }^{6}$ Data from the USA suggest that risky sex may have become more common in the mid-to-late 1950 s as penicillin became more widely available. ${ }^{7}$ As a result, the new curability of syphilis may have been partly responsible for syphilis case increases in Britain during the late 1950 s and early 1960 s.

\section{Adam Gilbertson, ${ }^{1,2,3}$ Adriane Gelpi, ${ }^{1,2}$ Joseph D Tucker ${ }^{1,4}$}

${ }^{1}$ Institute for Global Health and Infectious Diseases, University of North Carolina at Chapel Hill, Chapel Hill, North Carolina, USA

${ }^{2}$ Social Medicine Department, University of North Carolina at Chapel Hill, Chapel Hill, North Carolina, USA

${ }^{3}$ School of Anthropology and Museum Ethnography, University of Oxford, Oxford, UK

${ }^{4}$ International Diagnostics Centre, London, UK

Correspondence to Dr Joseph D Tucker, International Diagnostics Centre, Keppel Street, WCE1, London, UK; joseph.tucker@post.harvard.edu

Acknowledgements The authors would like to thank Dr Lesley Hall at the Wellcome Library and Dr Kevin Brown at the Alexander Fleming Laboratory Museum for archival assistance and Catie Gliwa for administrative assistance.

Contributors $A G, A G$ and JT were involved in drafting the manuscript, revising it and approving the final version.

Funding Support for this work was provided by the Brocher Foundation, the UNC Center for AIDS Research (NIAID P30-Al50410) and the Social and Ethical Aspects of Research on Curing HIV Working Group (NIAID R01A108366-01). The Working Group's composition and rationale are explained at http:// searchiv.web.unc.edu/
Competing interests None.

Provenance and peer review Commissioned; internally peer reviewed.

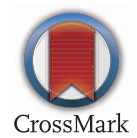

To cite Gilbertson A, Gelpi A, Tucker J D. Sex Transm Infect 2015;91:70-71.

Received 7 September 2014

Accepted 27 September 2014

Sex Transm Infect 2015;91:70-71.

doi:10.1136/sextrans-2014-051783

\section{REFERENCES}

1 King A. These dying diseases: venerology in decline. Lancet 1958;7022:651-7.

2 Moore JE. Venereology in transition. $\mathrm{Br} J$ Venereol 1956;32:217-25.

3 Adler MW. History of the development of a service for the venereal diseases. J $R$ Soc Med 1982;75:124-28.

4 Lee R. The teaching of venereology. $\mathrm{Br}$ I Venereol 1949;25:16-21.

5 Lees R. VD-Some random reflections of a venereologist. Br J Venereol 1950;26:163.

6 Tucker JD. The social and policy context of curing syphilis. Arch Sex Behav 2013;42:1381.

7 Francis AM. The wages of sin: how the discovery of penicillin reshaped modern sexuality. Arch Sex Behav 2013;42:5-13. 